\title{
High salinity changes in response to tectonic restriction in the Upper Miocene of Mediterranean
}

\author{
G.A. ButiseaCA ${ }^{1 *}$, G. KONTAKIOTIS ${ }^{2}$, E. Besiou ${ }^{2}$, K. \\ AGIADI $^{2}$, A. ANTONARKOU ${ }^{2}$, A. MULCH ${ }^{1,3}$, I.VASILIEV ${ }^{1}$ \\ ${ }^{1}$ Senckenberg Biodiversity and Climate Research Centre BiK- \\ F, Senckenberganlage 25, D-60325 Frankfurt am Main, \\ Germany (*geanina.butiseaca@senckenberg.de, \\ andreas.mulch@senckenberg.de, iuliana.vasiliev- \\ popa@senckenberg.de) \\ ${ }^{2}$ National and Kapodistrian University, Department of \\ Historical Geology and Paleontology, Faculty of Geology \\ and Geoenvironment, Panepistimioupolis 15784 Athens, \\ Greece (gkontak@geol.uoa.gr, wwweua@hotmail.com, \\ kagiadi@geol.uoa.gr, aantonar@geol.uoa.gr) \\ ${ }^{3}$ Goethe University, 60438 Frankfurt am Main, Germany.
}

\section{Context and methodology}

During the Messinian the Mediterranean Basin represented a world of hydrologic and climatic extremes that culminated with the renowned Messinian Salinity Crisis. The Basin-wide changes were mainly driven by closure of marine connections to the Atlantic (Riffian and Betic corridors) coeval with precession-driven climate fluctuations. Here we reconstruct sea surface salinity (SSS) in the Eastern Mediterranean for the time interval between 7.2 and $6.5 \mathrm{Ma}$. For this purpose we combine isoprenoidal GDGT TEX $\mathrm{T}_{86}$ sea surface temperatures (SST) with $\delta^{18} \mathrm{O}$ on planktonic foraminifera (Globigerinoides obliqus) assuming a constant relationship between $\delta^{18} \mathrm{O}$ of sea water and SSS through time.

\section{Results and discutions}

The SST and SSS records are characterized by three main events: between $\sim 7.2$ and 6.9 Ma SST values show low variability with rather lower salinities ( $\sim 36 \mathrm{psu}$, normal marine conditions) followed by a rapid increase in SST and SSS (up to 44 psu, hypersaline conditions) until $6.8 \mathrm{Ma}$. A marked cooling event occurs between 6.8-6.72 Ma coinicident with a decrease in SSS. At 6.72 Ma both SST and SSS shift to much higher values and higher variability until about 6.5 Ma. It is remarkable that during this period preceding the MSC, SSS increases at times when SST is high, a phenomenon completely opposite to other restriction events such as MSC.

We hypotesize that time intervals with increased SST and SSS values reflect the response to tectonic restriction superimposed on a microclimate driven by shifting of Saharan winds northwards over the Mediterranean. 